\title{
Detection of Unbalance in Rotating Machines Using Shaft Deflection Measurement during Its Operation
}

\author{
Md. Abdul Saleem ${ }^{1}$, G. Diwakar ${ }^{2}$, Dr. M.R.S. Satyanarayana ${ }^{3}$ \\ ${ }^{1}$ M.Tech Student, ${ }^{2}$ Assoc. Professor, Mech. Engg. Dept, Prasad V. Potluri Siddhartha Institute of Technology, \\ Kanuru, Vijayawada, Andhra Pradesh, India-520007. \\ ${ }^{3}$ Vice Principal, Mech. Engg. Dept, Gitam University, Visakhapatnam, Andhra Pradesh, India.
}

\begin{abstract}
Vibrations are found almost everywhere in rotating machines. Vibrations in rotating machinery are commonly the result of mechanical faults including mass unbalance, coupling misalignment, mechanical looseness, and many other causes. Unbalance is the most cause of machine vibration, an unbalanced rotor always cause more vibration and generates excessive force in the bearing area and reduces the life of the machine. In this paper 'Deflected Shape of Shaft' (DSS) of a rotating machine was found for detecting unbalance in its rotating components. The change in deflection shape gives the presence of unbalance in the shaft. Experiment reveals that a significant change in the DSS as an early warning indicator of unbalance in the rotating components. Tests were performed on a machinery fault simulator under various conditions of unbalance. Vibration data in terms of displacement was simultaneously acquired using a FFT (Fast Fourier Transform). The rotor shaft displacements were measured at different speeds using FFT at both unbalanced and balanced condition. The experimental frequency spectra were taken for both balanced and unbalanced condition. The presence of unbalance produces a change in the DSS at the rotor running speed and this data was extracted by conducting the experiments. A comparison was then performed with the theoretical calculation and also the vibration data acquired from FFT, at different running speeds. The results of this work provide a new method for detecting machinery unbalance, and offer a simplified approach for on-line fault detection in operating machinery.
\end{abstract}

Keywords: Unbalance, Vibration, Deflected Shape of Shaft (DSS), Fast Fourier Transform (FFT)

Nomenclature:

MNDE: Motor Non Drive End; $\quad$ H: Horizontal; $\quad$ D: Displacement

MDE: Motor Drive End; $\quad$ V: Vertical; $\quad$ Theo: Theoretical

PBE: Pillow Block End; A: Axial Exp: Experimental

\section{Introduction}

Rotor unbalance is the most common reason in machine vibrations. Most of the rotating machinery problem can be solved by using the rotor balancing and misalignment. Mass unbalance in a rotating system often produces excessive synchronous forces that reduce the life span of various mechanical elements. A very small amount of unbalance may cause severe problem in high speed rotating machines. Overhung rotors are used in many engineering applications like pump, fans, propellers and turbo machinery. The vibration signature of the overhung rotor is totally different from the center hung rotors. The vibration caused by unbalance may destroy critical parts of the machine, such as bearings, seals, gears and couplings. Rotor unbalance is a condition in which the centre of mass of a rotating assembly, typically the shaft and its fixed components like disks and blades etc. is not coincident with the centre of rotation. In practice, rotors can never be perfectly balanced because of manufacturing errors such as porosity in casting, non-uniform density of material, manufacturing tolerances and gain or loss of material during operation. As a result of mass unbalance, a centrifugal force is generated and must be reacted against by bearing and support structures.

Surendra N. Ganeriwala et al. [1] has demonstrated the use of the operational deflection shape (ODS) of a rotating machine as a means of detecting unbalance in its rotating components. The results of this work provide a new method for detecting machinery unbalance and offer a simplified approach for on-line fault detection in operating machinery.

Zhunag li et al. [2] has demonstrated the effects of rotating machinery shaft misalignment on its dynamic behavior which is characterized in the form of an Operational Deflection Shape (ODS). In this approach, an ODS derived from multiple accelerometer signals acquired at various points on the machine is used to diagnose shaft misalignment. Tests are performed on a machinery fault simulator under various operating conditions. Operating data is simultaneously acquired using a multi-channel data acquisition system.

William W. Clark et al. [3] has used technique for measuring and actively controlling dynamic bearing loads in rotating machinery subject to periodic excitations. Bearing loads are estimated using the Deflection- 
Detection of Unbalance in Rotating Machines Using Shaft Deflection Measurement during Its

Coefficient Method, a technique which does not rely on a full system model, and which applies commonly-used shaft-deflection measurement equipment to obtain estimates of bearing loads.

Kevin Gatzwiller et al. [4] describes the concept and the basic technique of measuring torsional operational deflection shapes using the Torsional Vibration Meter Type 2523, the Multichannel Analysis System Type 3550 and the Operational Deflection Shapes Software WT 9380, running on a Personal Computer.

Mark H. Richardson et al. [5] describes the mode shapes and operating "deflection" shapes are related to one another. In fact, one is always measured in order to obtain the other. Yet, they are quite different from one another in a number of ways. These articles discuss the relationships between modal testing, modal analysis and operating deflection shape measurements.

Unfortunately, other common faults can also generate high levels of vibration at 1xRPM including coupling misalignment, looseness, rotor bows, and a variety of other sources. In some cases, these faults will produce other symptoms that can suggest corrections other than balancing should be done. Yet in many cases, balancing may be the chosen course of action for lowering vibration amplitudes even though it is not the source of vibration.

\subsection{Unbalance and Vibration}

Unbalance occurs in a rotating machine when the mass centerline and the geometric center do not coincide on each other. Unbalanced rotors generate vibration which may damage their components. In order to extend the life of the machine, vibration due to unbalance must be reduced to acceptable level. Despite the ability to reduce unbalance to low levels, these levels or limits must be defined.

Unbalance amount is expressed as:

$$
\mathbf{U}=\mathbf{m}^{*} \mathbf{r}
$$

Where, $\mathrm{m}=$ unbalance mass (in $\mathrm{kg}$ )

$\mathrm{r}=$ distance from unbalance mass to shaft/rotor centerline (in $\mathrm{m}$ )

The unbalance force generating the vibration is expressed as:

$$
\mathbf{F}=\mathbf{m} * \mathbf{r} * \omega^{2}
$$

Where, $\mathrm{F}=$ force $(\mathrm{N})$

$\mathrm{m}=\operatorname{mass}(\mathrm{kg})$

$\mathrm{r}=\operatorname{radius}(\mathrm{m})$

$\omega=$ speed $(\mathrm{rad} / \mathrm{sec})$

Unbalance Vibration $=$ Unbalance Force/Dynamic Stiffness

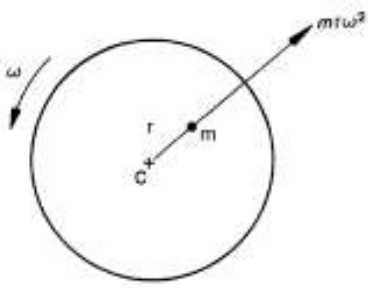

Fig 1.1 Centrifugal Force

There is no handy recognizable general relation between rotor unbalance and the machine vibrations. The unbalance response depends essentially on speed, the geometric proportions and mass distribution of rotor, as well as on the dynamic stiffness of the shaft, bearings and the foundation., For a particular rotor, unbalance vibration will have different values depending on its operating speed, type of bearings (e.g. fluid film or rolling element), foundation etc. while the unbalance amount itself is constant and only related to the rotor. So, the balancing quality limit should not be oversimplified and given through vibration readings only. This is especially true for new machines for which no pervious vibration experience exists.

An unbalanced rotating machine can cause parts to wear out quickly, and account for a significant percentage of a machine's downtime. Not only is downtime expensive in terms of lost production, but costs of replacement parts, inventory, and energy consumption are also increased. Traditionally, vibration signatures (level profiling of single point vibration spectra), and orbit plots have been the preferred tools for detecting and diagnosing machinery unbalance. Although these tools may be effective when used by an expert, 'Deflected Shape of Shaft' (DSS) analysis offers a simpler, more straightforward approach for fault detection. Unbalance is more easily characterized by a visual as well as a numerical comparison of a machine's DSS when compared with its theoretical calculation and vibration data.

A DSS is defined as any motion of two or more points on a machine or structure. Stated differently, a DSS is the motion of one point relative to all others. Motion is a vector quantity, and each of its components has both location and direction associated with it. Motion measured at a point in a specific direction is called a DOF (Degree of Freedom). A DSS can be defined from any measured vibration data, either at a moment in time, or at a specific frequency. A DSS can be obtained from different types of time domain responses, e.g. random, impulsive, or sinusoidal. A DSS can also be obtained from different types of frequency domain functions including linear spectra (FFTs).

\section{Description Of The Experimental Setup}

The Experimental apparatus consists of a $0.5 \mathrm{Hp}$ A.C. Induction motor, a fixed type flange coupling and a single disk rotor as shown in Figure $2 \&$ 3.The rotor shaft has a length of $1000 \mathrm{~mm}$ with a bearing span of $750 \mathrm{~mm}$, and is supported by a single identical ball bearing (pillow block) as shown in Fig.3. The diameter of 
Detection of Unbalance in Rotating Machines Using Shaft Deflection Measurement during Its

the rotor shaft is $16 \mathrm{~mm}$. A disk of $220 \mathrm{~mm}$ in diameter and $6 \mathrm{~mm}$ in thickness is mounted on the rotor shaft at the overhang end. The rotor shaft is driven by $0.5 \mathrm{Hp} \mathrm{A.C.} \mathrm{motor.} \mathrm{The} \mathrm{speed} \mathrm{of} \mathrm{the} \mathrm{motor} \mathrm{is} \mathrm{controlled} \mathrm{by} \mathrm{using}$ VFD (Variable Frequency Drive) which is mainly used for A.C motors, to increase or decrease the speeds of the motor in the range of 500 to1440 rpm as shown in Fig.2. The instrument used in experiment includes FFT which measures the vibration in terms of displacement at MNDE, MDE \& PBE housing and gives the corresponding values.

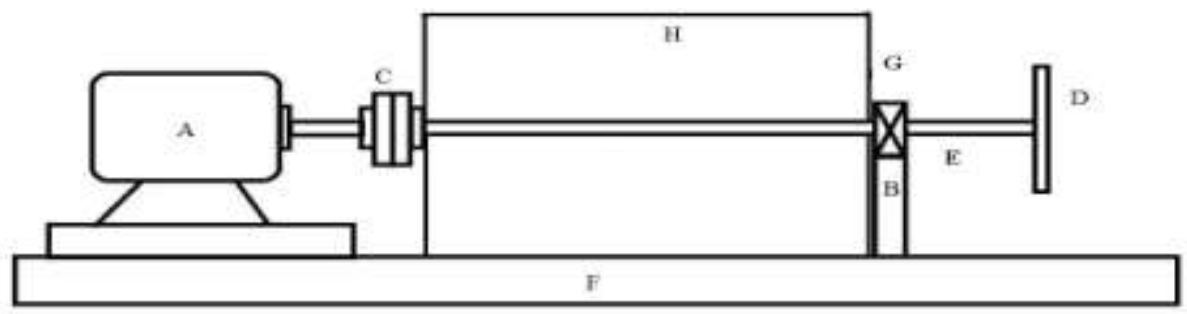

Fig 2.1 Line diagram of experimental setup.

A - A.C. Induction Motor, B - Bearing Support, C - Coupling, D - Disk, E - Rotor Shaft, F - Base, G - Pillow Block, H - Plywood Board

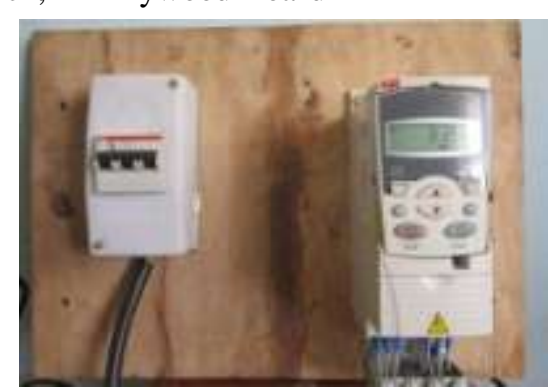

Fig 2.2 VFD (Variable Frequency Drive)

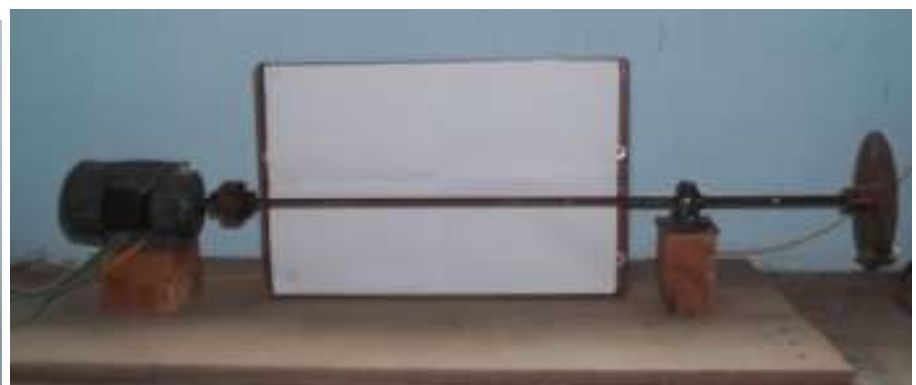

Fig 2.3 Experimental setup

\section{Experimental Procedure}

The experimental setup is as shown in Fig. 2 \& 3. First the setup is run for few minutes to settle down all minor vibrations. Before creating the unbalance, the shaft is checked for any misalignment and unbalance. After this an unbalance has been created by placing a mass in the overhung rotor at different eccentricities on the overhung disk. The shaft bow is taken with the help of a white chart placed on plywood board and with the help of pencil. The readings were taken at various unbalanced and balanced conditions at different speeds. Through this different waveforms are acquired and with the help of these waveforms, the Deflected Shape of Shaft (DSS) is drawn. Using the coordinates of the curve obtained the deflection value is measured.

The masses \& eccentricities considered in our experiments are:

1. Mass, $\mathrm{m}_{1}=142 \mathrm{gm}$.

2. Eccentricity, $\mathrm{e}_{1}=70 \mathrm{~mm}$.

3. Eccentricity, $\mathrm{e}_{2}=100 \mathrm{~mm}$.

FFT is the vibration analyzer used to acquire the vibration signals in terms of displacement signals. Vibration signals are measured at different speeds $600,700,800 \mathrm{rpm}$ with the unbalanced rotor system at Motor Non-Drive End (MNDE) and Motor Drive End (MDE) and Pillow Block End (PBE) stored in the vibration analyzer. And same masses were added at exact opposite direction i.e. in balanced state and vibration signals were taken.

To verify our hypothesis, tests were performed using the machinery fault simulator shown in Figure 3. With the help of FFT the transducer was attached in horizontal, vertical and axial directions of bearing housings and the motor. This transducer provided a total of vibration signals which were simultaneously acquired with support of MCME 2.0 software in the computer.

\subsection{Unbalance Conditions}

Vibration data was acquired from the machine when it was considered to be in unbalance, and under two different unbalance conditions, at different speeds. Unbalance was created by adding weights to the rotors on the simulator, at various eccentricities $\mathrm{e}_{1}$ and $\mathrm{e}_{2}$. Data was acquired for each of the following unbalance conditions.

Case 1: At eccentricity $\mathrm{e}_{1}$, with mass $\mathrm{m}_{1}$

Case 2: At eccentricity $\mathrm{e}_{2}$, with mass $\mathrm{m}_{1}$ 


\subsection{Balance Conditions}

Similarly vibration data was acquired from the machine when it was considered to be in balance, and under two different balance conditions, at different speeds. Balance was created by adding weights to the rotors opposite direction on the same radial line of equal distances on the disk of the simulator, at various eccentricities $\mathrm{e}_{1}$ and $\mathrm{e}_{2}$. Data was acquired for each of the following balance conditions.

Case 3: At eccentricity $e_{1}$, with mass $m_{1}$

Case 4: At eccentricity $\mathrm{e}_{2}$, with mass $\mathrm{m}_{1}$

\subsection{Theoretical Calculation}

\section{Formulation} follows:

Deflection between supports is calculated and formulated as

$$
\square_{\mathbf{x}}=\left[(1 / 24 \text { Eil }) * \mathrm{wx}\left(\mathrm{l}^{4}-2 \mathrm{l}^{2} \mathrm{x}^{2}+1 \mathrm{x}^{3}-2 \mathrm{a}^{2} \mathrm{l}^{2}+2 \mathrm{a}^{2} \mathrm{x}^{2}\right)\right]+\left[(\text { Pax/6Eil }) *\left(1^{2}-\mathrm{x}^{2}\right)\right]
$$

Where, $\square_{\mathbf{x}}=$ Deflection

$\mathrm{E}=$ Young's modulus

$\mathrm{i}=$ Moment of Inertia

$1=$ Length of the shaft between supports

$\mathrm{a}=$ Overhang length of the shaft

$\mathrm{x}=$ Distance from left end support

$\mathrm{w}=$ Uniformly Distributed Load

$\mathrm{P}=$ Load at the end

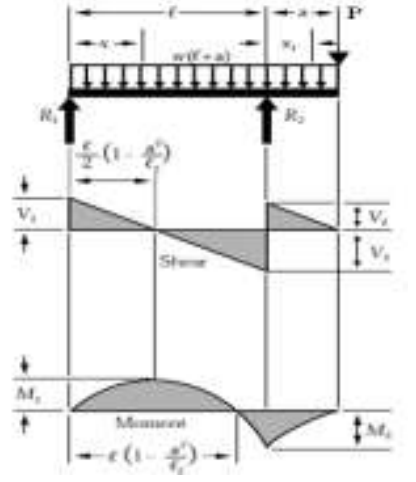

Fig 4.1 Overhanging Beam

\subsection{Experimental Results}

The experimental deflection at various positions of shaft in unbalance condition are taken by considering the case $1 \& 2$ in unbalance condition and case $3 \& 4$ in balance condition, at three different speeds of $600,700 \& 800 \mathrm{rpm}$, we get the following experimental results.

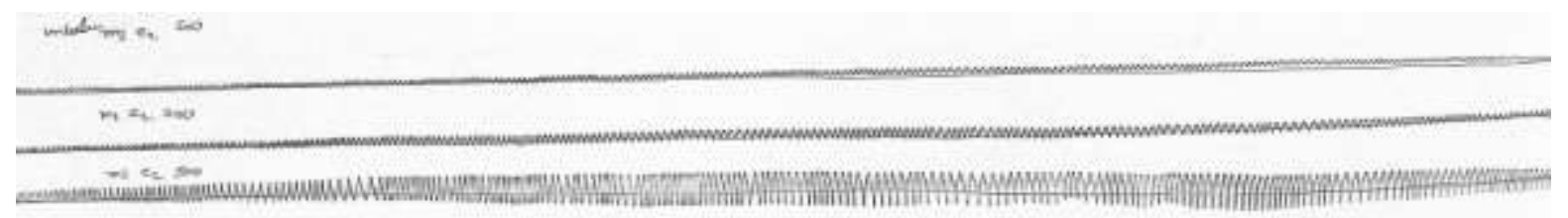

Fig 4.2 Experimental result of case 1 in unbalance condition

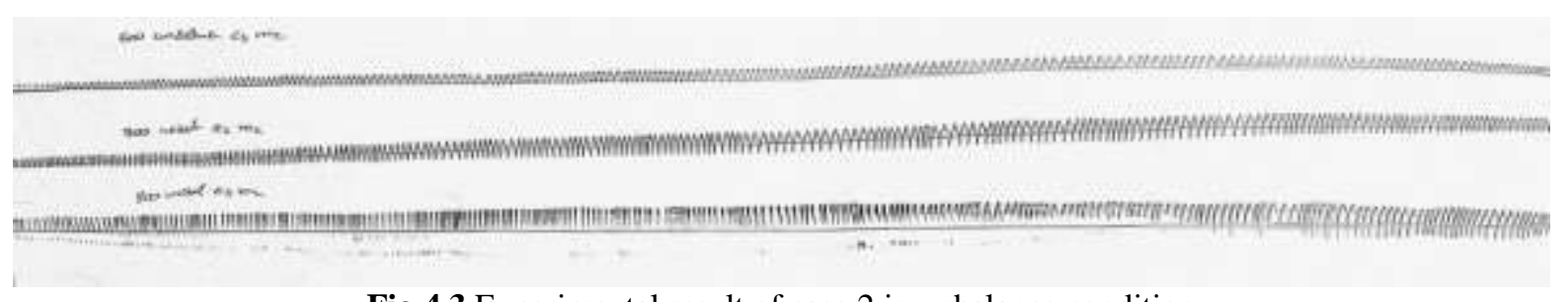

Fig 4.3 Experimental result of case 2 in unbalance condition

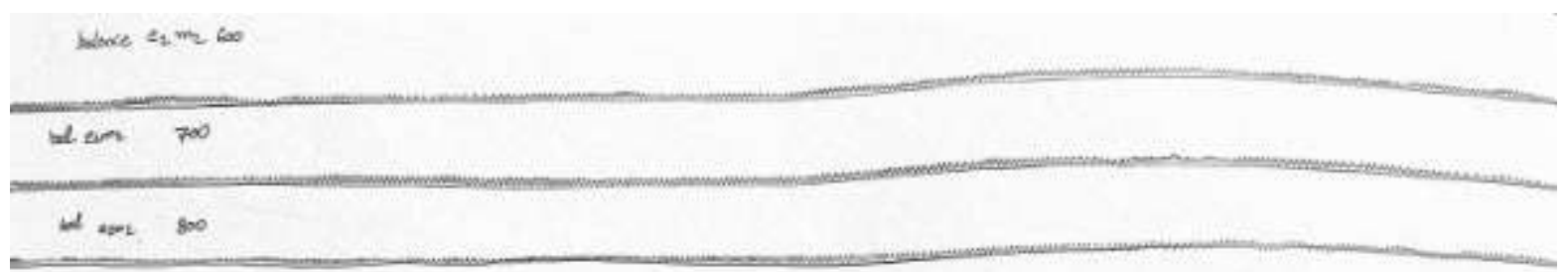

Fig 4.4 Experimental result of case 3 in balance condition 
Fig 4.5 Experimental result of case 4 in balance condition

\subsection{Comparison of Theoretical and Experimental Deflection at Various Positions of Shaft in Unbalance Condition}

The theoretical values are determined by using general solid mechanics with the help of $\mathrm{C}$ program and the values are presented below. Experimental values are taken from charts of deflected shapes of shaft shown above.

\begin{tabular}{|c|c|c|c|c|c|c|}
\hline \multirow{2}{*}{$\mathrm{x}(\mathrm{mm})$} & \multicolumn{7}{|c|}{$\mathrm{y}(\mathrm{mm})$} \\
\cline { 2 - 7 } & \multicolumn{2}{|c|}{$600 \mathrm{rpm}$} & \multicolumn{2}{c|}{$700 \mathrm{rpm}$} & \multicolumn{2}{c|}{$800 \mathrm{rpm}$} \\
\cline { 2 - 7 } & Theo. & Exp. & Theo. & Exp. & Theo. & Exp. \\
\hline 0 & 0 & 0 & 0 & 0 & 0 & 0 \\
\hline 80 & 0.23 & 0.25 & 0.28 & 0.5 & 0.35 & 0.5 \\
\hline 140 & 0.39 & 0.5 & 0.49 & 0.75 & 0.59 & 1 \\
\hline 200 & 0.54 & 0.75 & 0.67 & 1 & 0.82 & 1.5 \\
\hline 320 & 0.77 & 1 & 0.95 & 1.25 & 1.15 & 2.5 \\
\hline 420 & 0.85 & 1.25 & 1.04 & 1.5 & 1.27 & 3 \\
\hline 500 & 0.81 & 1 & 1.00 & 1.25 & 1.22 & 2.5 \\
\hline 560 & 0.72 & 0.75 & 0.9 & 1 & 1.09 & 1.5 \\
\hline 620 & 0.57 & 0.5 & 0.71 & 0.75 & 0.86 & 1 \\
\hline 700 & 0.26 & 0.25 & 0.32 & 0.5 & 0.39 & 0.5 \\
\hline 750 & 0 & 0 & 0 & 0 & 0 & 0 \\
\hline
\end{tabular}

Table: 1. Values determined for case 1

\begin{tabular}{|c|c|c|c|c|c|c|}
\hline \multirow{2}{*}{$\mathrm{x}(\mathrm{mm})$} & \multicolumn{7}{|c|}{$\mathrm{y}(\mathrm{mm})$} \\
\cline { 2 - 7 } & \multicolumn{2}{|c|}{$600 \mathrm{rpm}$} & \multicolumn{2}{c|}{$700 \mathrm{rpm}$} & \multicolumn{2}{c|}{$800 \mathrm{rpm}$} \\
\cline { 2 - 7 } & Theo. & Exp. & Theo. & Exp. & Theo. & Exp. \\
\hline 0 & 0 & 0 & 0 & 0 & 0 & 0 \\
\hline 80 & 0.29 & 0.5 & 0.37 & 0.5 & 0.46 & 1 \\
\hline 140 & 0.50 & 0.75 & 0.64 & 1 & 0.79 & 2 \\
\hline 200 & 0.69 & 1 & 0.88 & 1.5 & 1.09 & 3 \\
\hline 320 & 0.98 & 1.25 & 1.24 & 2 & 1.53 & 3 \\
\hline 420 & 1.08 & 1.5 & 1.36 & 2.5 & 1.69 & 3 \\
\hline 500 & 1.04 & 1.25 & 1.31 & 2 & 1.63 & 3 \\
\hline 560 & 0.93 & 1 & 1.17 & 1.5 & 1.45 & 3 \\
\hline 620 & 0.73 & 0.75 & 0.93 & 1 & 1.15 & 2 \\
\hline 700 & 0.33 & 0.5 & 0.42 & 0.5 & 0.53 & 1 \\
\hline 750 & 0 & 0 & 0 & 0 & 0 & 0 \\
\hline
\end{tabular}

Table: 2. Values determined for case 2

\subsection{Graphs show deflection at various positions of shaft in unbalance condition}

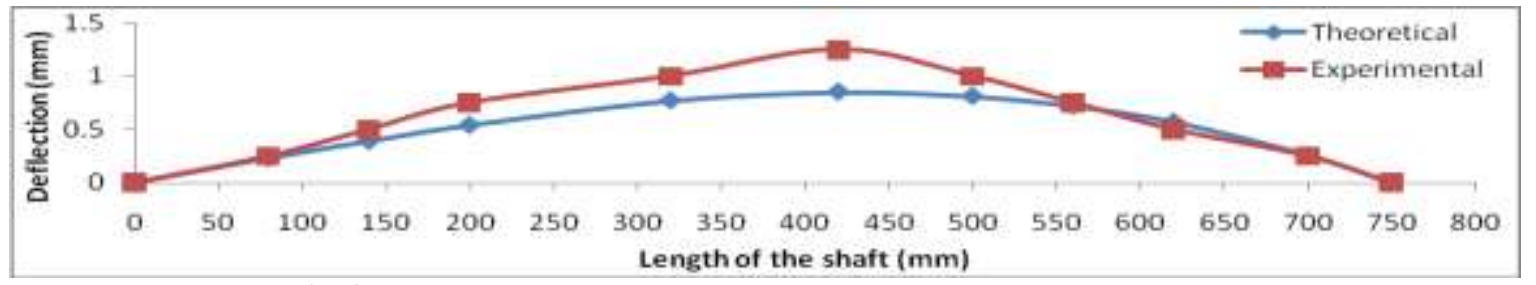

Fig 4.6 Theoretical and experimental deflection for case 1 at 600rpm

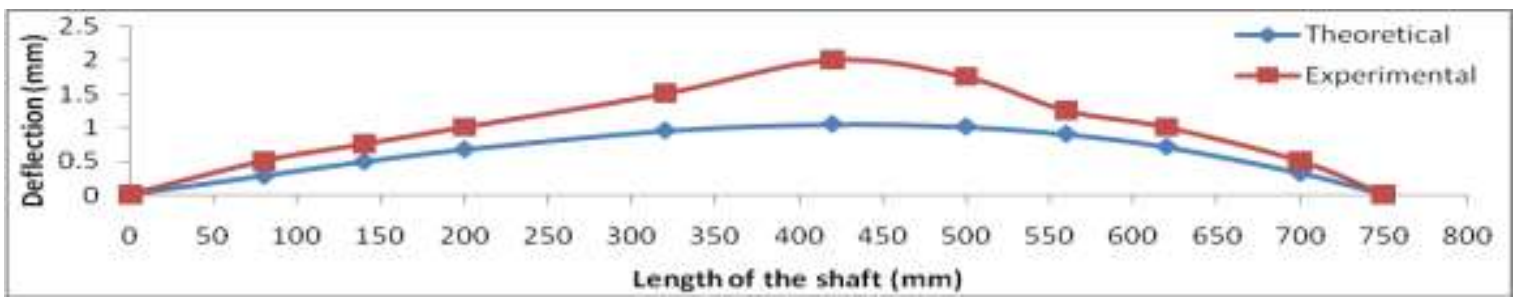

Fig 4.7 Theoretical and experimental deflection for case 1 at 700rpm

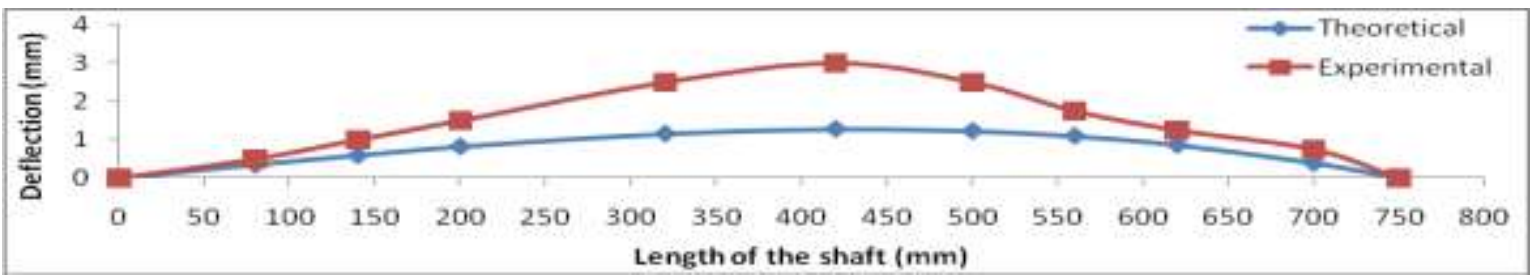

Fig 4.8 Theoretical and experimental deflection for case 1 at 800rpm 
Detection of Unbalance in Rotating Machines Using Shaft Deflection Measurement during Its

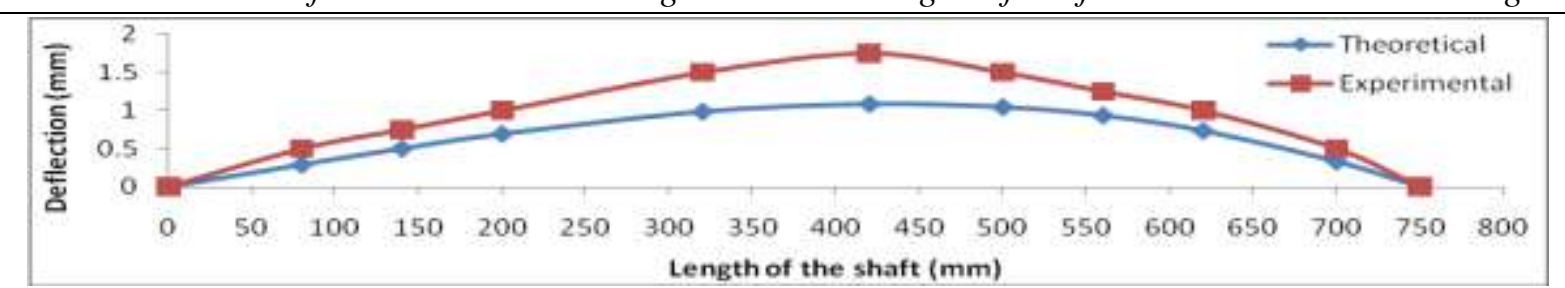

Fig 4.9 Theoretical and experimental deflection for case 2 at 600rpm

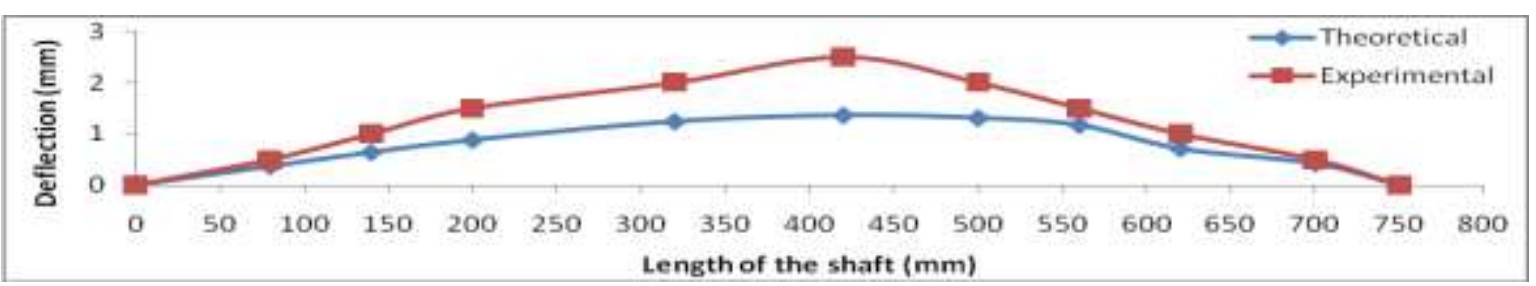

Fig 4.10 Theoretical and experimental deflection for case 2 at 700rpm

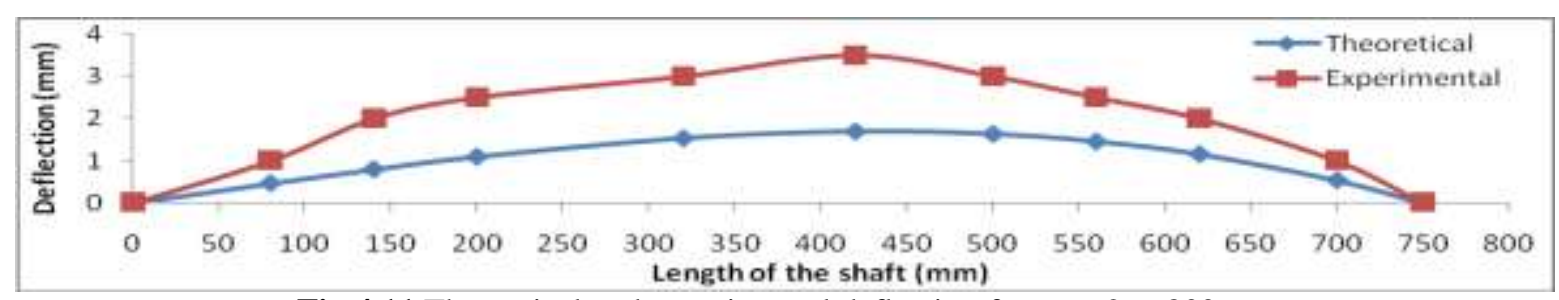

Fig 4.11 Theoretical and experimental deflection for case 2 at 800rpm

4.5 Comparison of Theoretical and Experimental Deflection at Various Positions of Shaft in Balance Condition

\begin{tabular}{|c|c|c|c|c|c|c|}
\hline \multirow{2}{*}{$\mathrm{x}(\mathrm{mm})$} & \multicolumn{7}{|c|}{$\mathrm{y}(\mathrm{mm})$} \\
\cline { 2 - 7 } & \multicolumn{2}{|c|}{$600 \mathrm{rpm}$} & \multicolumn{2}{c|}{$700 \mathrm{rpm}$} & \multicolumn{2}{c|}{$800 \mathrm{rpm}$} \\
\cline { 2 - 7 } & Theo. & Exp. & Theo. & Exp. & Theo. & Exp. \\
\hline 0 & 0 & 0 & 0 & 0 & 0 & 0 \\
\hline 80 & 0.08 & 0.25 & 0.08 & 0.5 & 0.08 & 0.5 \\
\hline 140 & 0.15 & 0.5 & 0.15 & 0.75 & 0.15 & 0.75 \\
\hline 200 & 0.21 & 0.75 & 0.21 & 1 & 0.21 & 1 \\
\hline 320 & 0.29 & 1 & 0.29 & 1 & 0.29 & 1 \\
\hline 420 & 0.32 & 1 & 0.32 & 1 & 0.32 & 1 \\
\hline 500 & 0.31 & 1 & 0.31 & 1 & 0.31 & 1 \\
\hline 560 & 0.28 & 0.75 & 0.28 & 1 & 0.28 & 1 \\
\hline 620 & 0.22 & 0.5 & 0.22 & 0.75 & 0.22 & 0.75 \\
\hline 700 & 0.10 & 0.25 & 0.10 & 0.5 & 0.10 & 0.5 \\
\hline 750 & 0 & 0 & 0 & 0 & 0 & 0 \\
\hline
\end{tabular}

Table: 3. Values determined for case 3

\begin{tabular}{|c|c|c|c|c|c|c|}
\hline \multirow{2}{*}{$\mathrm{x}(\mathrm{mm})$} & \multicolumn{7}{|c|}{$\mathrm{y}(\mathrm{mm})$} \\
\cline { 2 - 7 } & $600 \mathrm{rpm}$ & \multicolumn{2}{c|}{$700 \mathrm{rpm}$} & \multicolumn{2}{c|}{$800 \mathrm{rpm}$} \\
\cline { 2 - 7 } & Theo. & Exp. & Theo. & Exp. & Theo. & Exp. \\
\hline 0 & 0 & 0 & 0 & 0 & 0 & 0 \\
\hline 80 & 0.09 & 0.5 & 0.09 & 0.5 & 0.09 & 0.5 \\
\hline 140 & 0.15 & 1 & 0.15 & 1 & 0.15 & 1 \\
\hline 200 & 0.21 & 1 & 0.21 & 1.5 & 0.21 & 1.5 \\
\hline 320 & 0.30 & 1 & 0.30 & 2 & 0.30 & 2 \\
\hline 420 & 0.33 & 1 & 0.33 & 2 & 0.33 & 2 \\
\hline 500 & 0.32 & 1 & 0.32 & 2 & 0.32 & 2 \\
\hline 560 & 0.29 & 1 & 0.29 & 1.5 & 0.29 & 1.5 \\
\hline 620 & 0.23 & 1 & 0.23 & 1 & 0.23 & 1 \\
\hline 700 & 0.10 & 0.5 & 0.10 & 0.5 & 0.10 & 0.5 \\
\hline 750 & 0 & 0 & 0 & 0 & 0 & 0 \\
\hline
\end{tabular}

Table: 4. Values determined for case 4

\subsection{Graphs show deflection at various positions of shaft in balance condition}

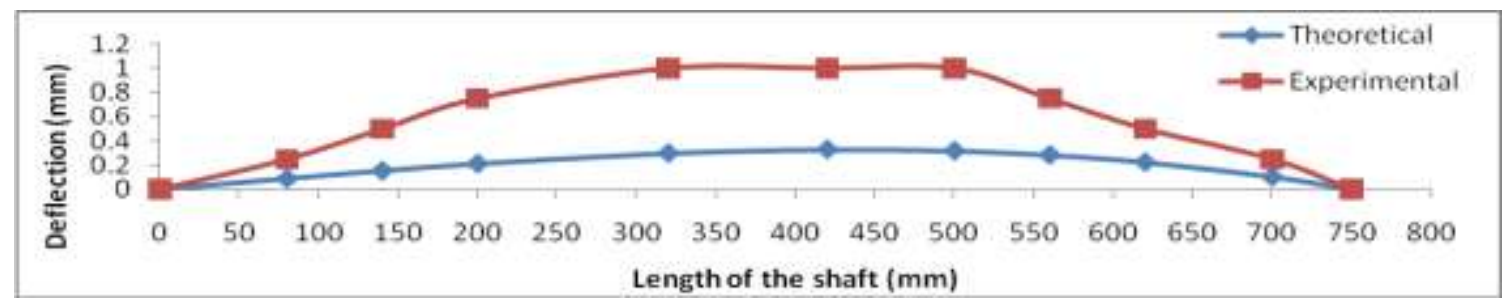

Fig 4.12 Theoretical and experimental deflection for case 3 at $600 \mathrm{rpm}$ 


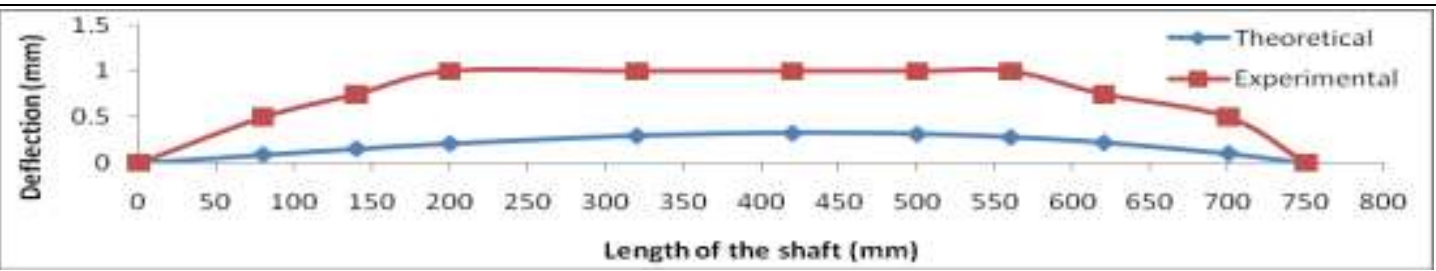

Fig 4.13 Theoretical and experimental deflection for case 3 at 700rpm

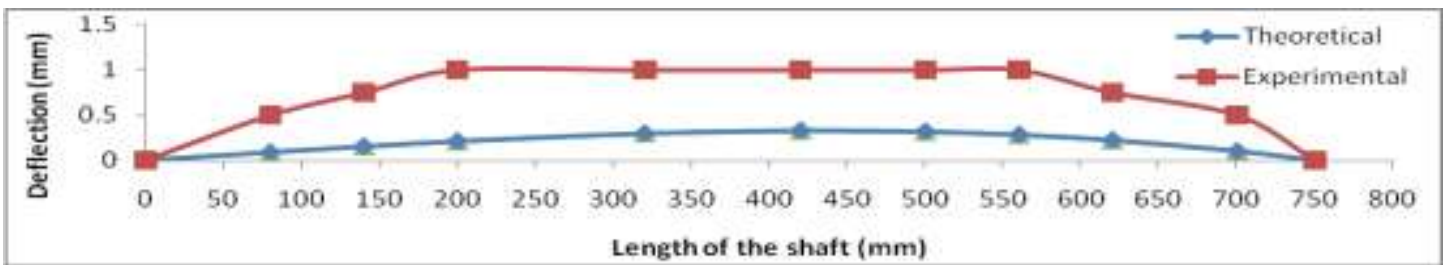

Fig 4.14 Theoretical and experimental deflection for case 3 at 800rpm

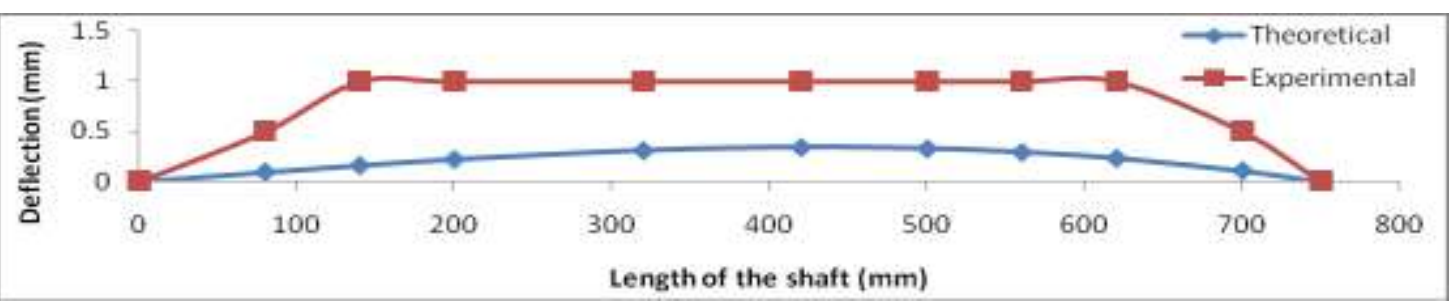

Fig 4.15 Theoretical and experimental deflection for case 4 at 600rpm

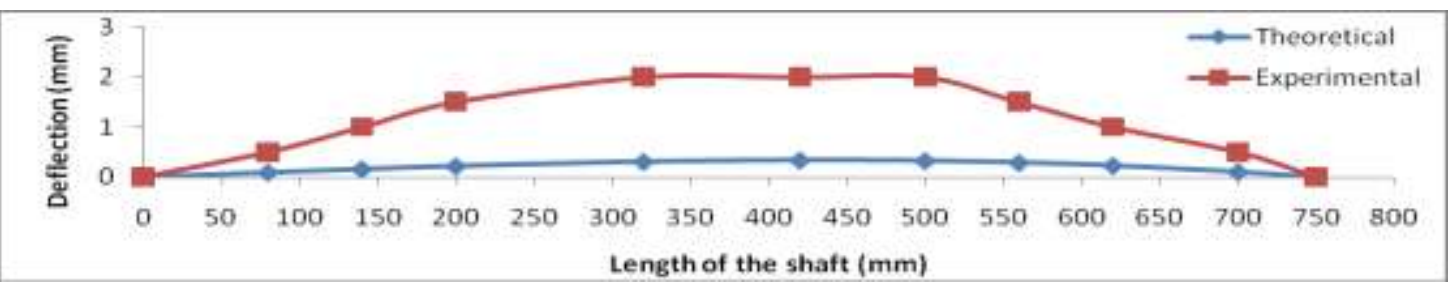

Fig 4.16 Theoretical and experimental deflection for case 4 at 700rpm

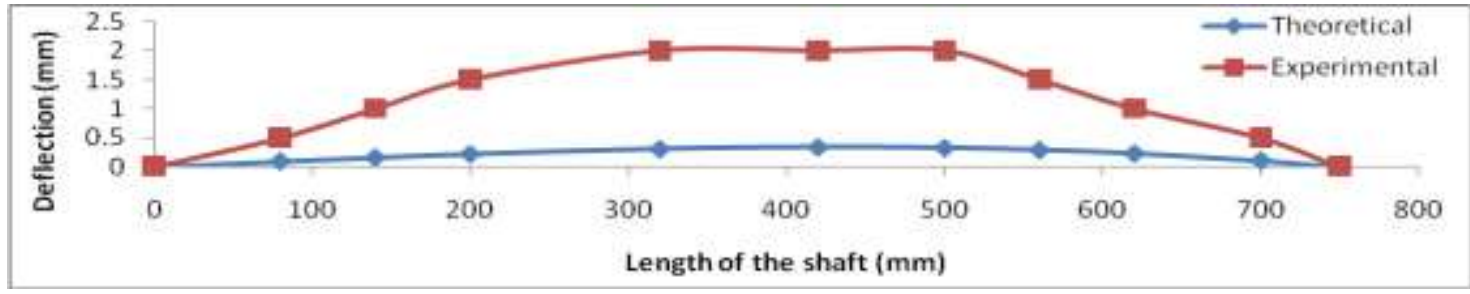

Fig 4.17 Theoretical and experimental deflection for case 4 at 800rpm

\section{Vibration Readings Observed Using FFT}

\subsection{Vibration readings at unbalanced condition for case 1}

\begin{tabular}{|l|c|c|c|c|c|c|c|c|c|}
\hline $\begin{array}{l}\text { Speed } \\
(\mathbf{r p m})\end{array}$ & \multicolumn{3}{|c|}{ MNDE } & \multicolumn{3}{c|}{ MDE } & \multicolumn{3}{c|}{ PBE } \\
\cline { 2 - 9 } & $\mathbf{H}$ & $\mathbf{V}$ & $\mathbf{A}$ & $\mathbf{H}$ & $\mathbf{V}$ & $\mathbf{A}$ & $\mathbf{H}$ & $\mathbf{V}$ & $\mathbf{A}$ \\
\hline $\mathbf{6 0 0}$ & 111 & 34.7 & 175 & 113 & 154 & 142 & 349 & 567 & 98.5 \\
\hline $\mathbf{7 0 0}$ & 207 & 44.2 & 296 & 213 & 209 & 219 & 688 & 1394 & 268 \\
\hline $\mathbf{8 0 0}$ & 444 & 112 & 857 & 487 & 579 & 823 & 1548 & 4004 & 799 \\
\hline
\end{tabular}

Table: 5

Above readings show that high vibrations are present at PBE. At all speeds vibrations in radial direction are higher than axial direction. High radial vibrations are present due to unbalance, misalignment and bending of the shaft. To determine the cause of high vibrations spectrum analysis was carried. Following are the spectrums taken at different speeds using FFT Analyzer with the support of Mcme2.0 software. 
Detection of Unbalance in Rotating Machines Using Shaft Deflection Measurement during Its

\subsection{Unbalanced Spectrum at Different Speeds}

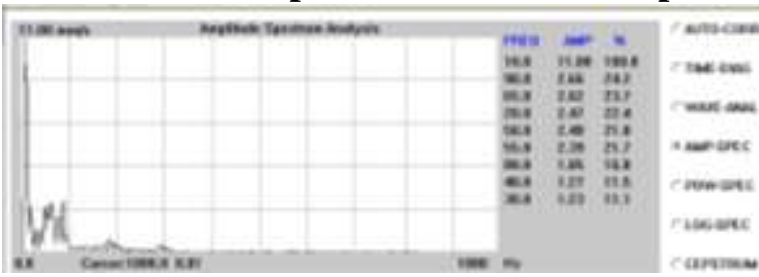

Spectrum in PBE HOZ direction at $600 \mathrm{rpm}$

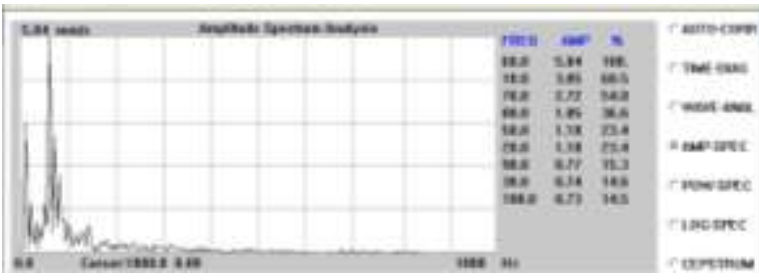

Spectrum in PBE AXL direction at $600 \mathrm{rpm}$

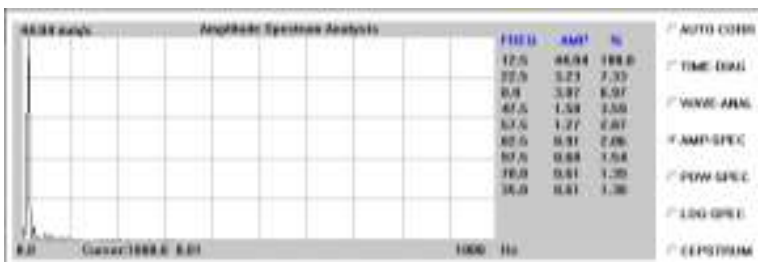

Spectrum in PBE VER direction at 700 rpm

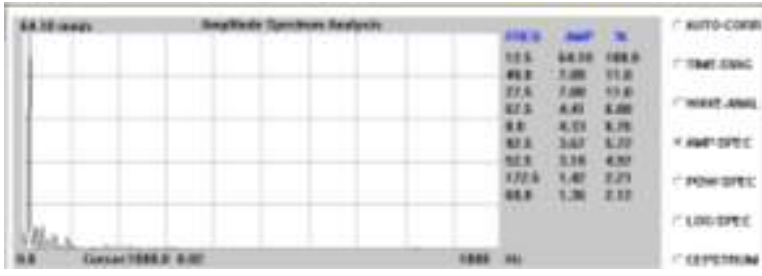

Spectrum in PBE HOZ direction at 800 rpm

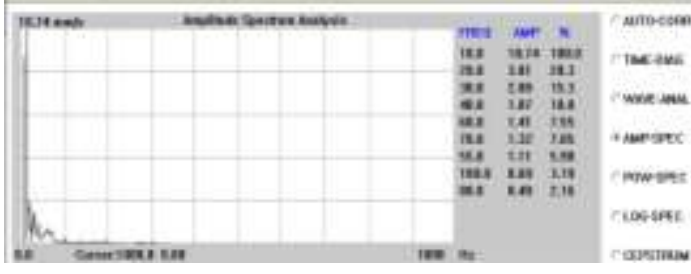

Spectrum in PBE VER direction at 600 rpm

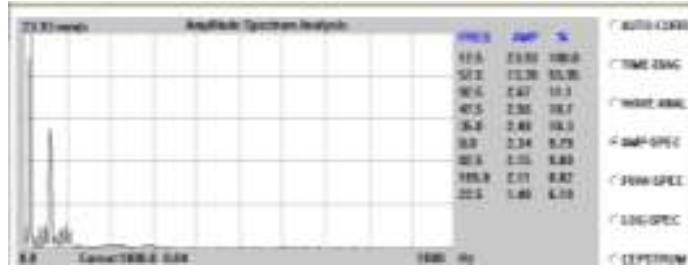

Spectrum in PBE HOZ direction at 700 rpm

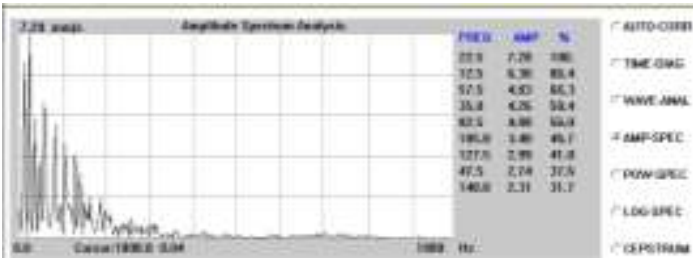

Spectrum in PBE AXL direction at 700 rpm

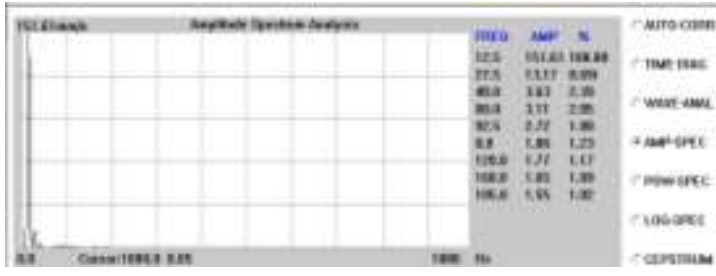

Spectrum in PBE VER direction at 800 rpm

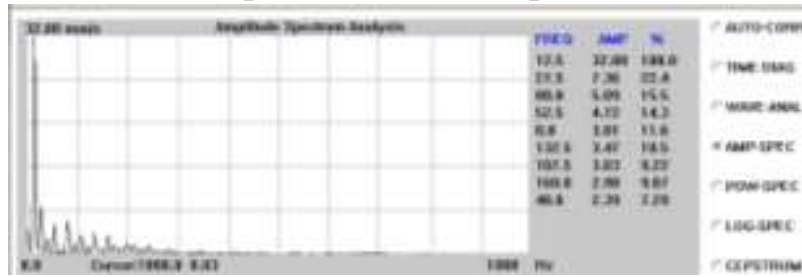

Spectrum in PBE AXL direction at 800 rpm

The following phase readings are also observed at PBE

\begin{tabular}{|c|ccccccc|c|}
\hline \multirow{2}{*}{$\begin{array}{c}\text { SPEED } \\
(\mathbf{r p m})\end{array}$} & \multicolumn{7}{|c|}{ DISPLACMENT in um } & \multirow{2}{*}{$\begin{array}{c}\text { PHASEANGLE } \\
\text { IN DEGREES }\end{array}$} \\
\cline { 2 - 9 } & $\mathbf{0}^{\mathbf{0}}$ & $\mathbf{3 0}^{\mathbf{0}}$ & $\mathbf{6 0}^{\mathbf{0}}$ & $\begin{array}{c}\text { At } \\
\mathbf{9 0}^{\mathbf{0}}\end{array}$ & $\mathbf{1 2 0}^{\mathbf{0}}$ & $\mathbf{1 5 0}^{\mathbf{0}}$ & $\mathbf{1 8 0}^{\mathbf{0}}$ & \\
\hline $\mathbf{6 0 0}$ & 89 & 104 & 102 & 40.9 & 65.7 & 103 & 47.7 & $60^{\circ}$ \\
\hline $\mathbf{7 0 0}$ & 164 & 213 & 277 & 367 & 174 & 107 & 60.6 & $90^{\circ}$ \\
\hline $\mathbf{8 0 0}$ & 629 & 785 & 668 & 952 & 858 & 877 & 738 & $90^{\circ}$ \\
\hline
\end{tabular}

Table: 6

\subsection{Observations from Spectrums}

1. In all the spectrums of pillow block end $1 \mathrm{X}$ and its harmonics are present.

2. No bearing defective frequency peaks are present in the pillow block spectrums.

3. The values at MNDE axial are high because of the looseness of the cup of motor.

4. In the pillow block at $800 \mathrm{rpm}$ vertical spectrum " $1 \mathrm{X}$ " is predominant and having highest value $4004 \mu \mathrm{m}$.

5. High " $1 X$ " amplitudes in PBE horizontal and vertical spectrum indicates abnormal condition such as unbalance, misalignment, looseness or resonance condition.

6. To determine the exact cause of high vibrations phase readings are taken as shown in table above. 
Detection of Unbalance in Rotating Machines Using Shaft Deflection Measurement during Its

\subsection{Observation from Phase Analysis}

1. From the phase reading at the PBE it is observed that there is $90^{\circ}$ phase difference between the PBE horizontal and vertical.

2. $90^{\circ}$ phase difference between horizontal and vertical reveals that there is presence of an unbalance at PBE.

3. From the spectrum analysis and phase analysis it is conformed that there is a presence of mass unbalance in the PBE.

Rotor was removed and balanced weight is added diametrically opposite to unbalanced mass and vibration readings were taken after balancing. Vibration readings are shown in following table.

\subsection{Vibration readings at balanced condition for case 3}

\begin{tabular}{|l|c|c|c|c|c|c|c|c|c|}
\hline \multirow{2}{*}{$\begin{array}{c}\text { Speed } \\
(\mathbf{r p m})\end{array}$} & \multicolumn{3}{|c|}{ MNDE } & \multicolumn{3}{c|}{ MDE } & \multicolumn{3}{c|}{ PBE } \\
\cline { 2 - 10 } & $\mathbf{H}$ & $\mathbf{V}$ & $\mathbf{A}$ & $\mathbf{H}$ & $\mathbf{V}$ & $\mathbf{A}$ & H & V & A \\
\hline $\mathbf{6 0 0}$ & 44.5 & 27.7 & 82 & 48.5 & 56.6 & 63.7 & 66.8 & 108 & 38 \\
\hline $\mathbf{7 0 0}$ & 76.2 & 30.7 & 159 & 73.4 & 133 & 149 & 155 & 169 & 39.4 \\
\hline $\mathbf{8 0 0}$ & 261 & 42.3 & 857 & 264 & 170 & 374 & 693 & 528 & 148 \\
\hline
\end{tabular}

\subsection{Balanced spectrum at different speeds}

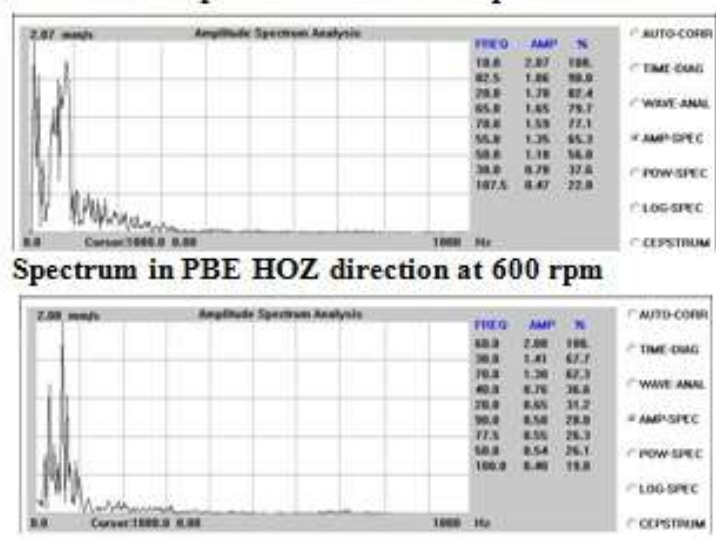

Spectrum in PBE AXL direction at $600 \mathrm{rpm}$

Table: 7

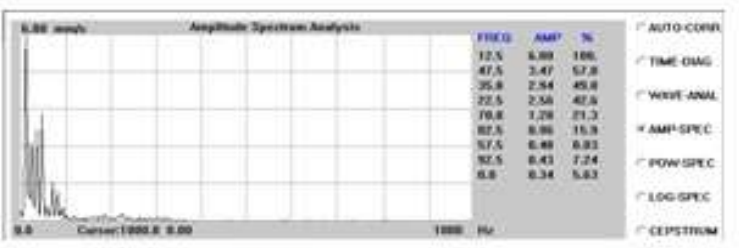

Spectrum in PBE VER direction at $700 \mathrm{rpm}$

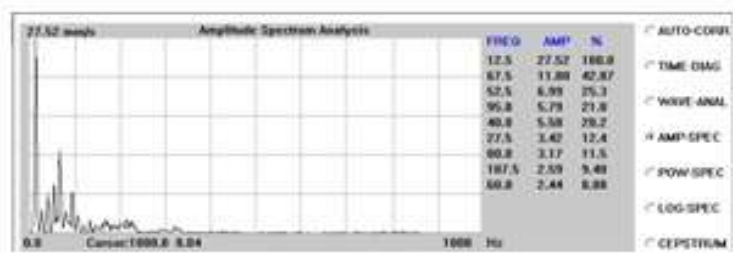

Spectrum in PBE HOZ direction at $800 \mathrm{rpm}$

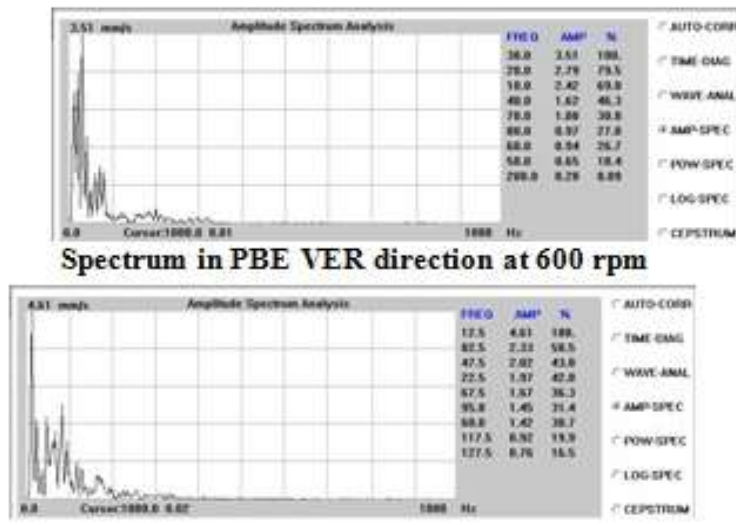

Spectrum in PBE HOZ direction at $700 \mathrm{rpm}$

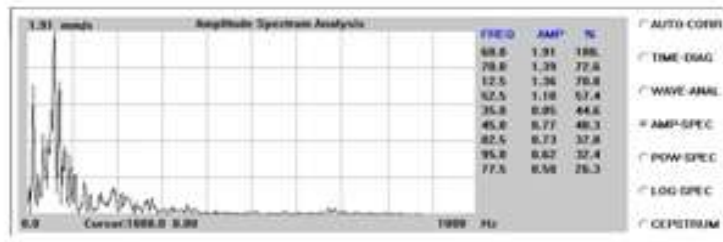

Spectrum in PBE AXL direction at $700 \mathrm{rpm}$

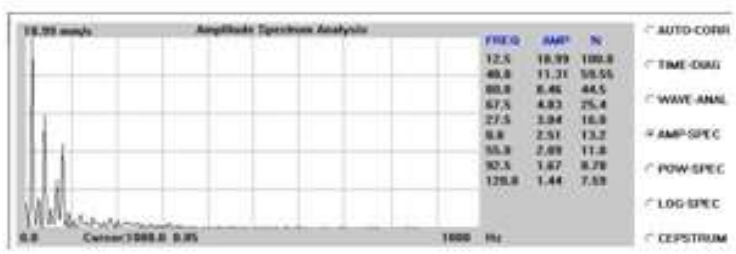

Spectrum in PBE VER direction at $800 \mathrm{rpm}$

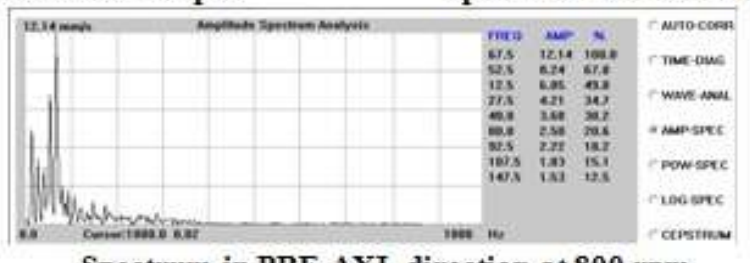

Spectrum in PBE AXL direction at $800 \mathrm{rpm}$

\subsection{Observations from spectrums}

1. The values at MNDE axial are high because of the looseness of the cup of the motor at non-drive end.

2. All vibration readings show that the readings were reduced to normal level. 
Detection of Unbalance in Rotating Machines Using Shaft Deflection Measurement during Its

5.8 Graphs show Vibration amplitude against speed, comparison with unbalance and balance

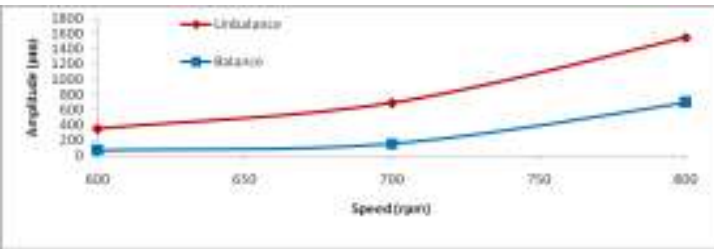

Vibration amplitude at PBE HOZ against speed

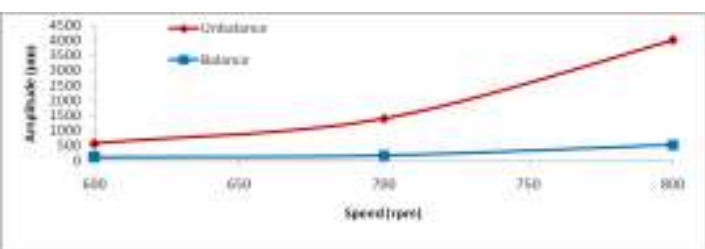

Vibration amplitude at PBE VER against speed

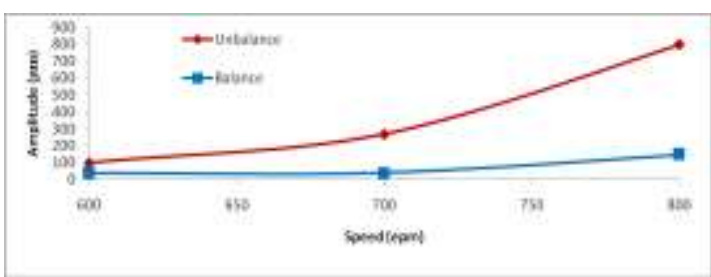

Vibration amplitude at PBE AXL against speed

\subsection{Vibration readings at unbalanced condition for case 2}

\begin{tabular}{|l|c|c|c|c|c|c|c|c|c|}
\hline \multirow{2}{*}{$\begin{array}{c}\text { Speed } \\
(\mathbf{r p m})\end{array}$} & \multicolumn{3}{|c|}{ MNDE } & \multicolumn{3}{c|}{ MDE } & \multicolumn{3}{c|}{ PBE } \\
\cline { 2 - 10 } & $\mathbf{H}$ & $\mathbf{V}$ & $\mathbf{A}$ & $\mathbf{H}$ & $\mathbf{V}$ & $\mathbf{A}$ & $\mathbf{H}$ & V & A \\
\hline $\mathbf{6 0 0}$ & 189 & 142 & 591 & 216 & 199 & 472 & 1489 & 1414 & 334 \\
\hline $\mathbf{7 0 0}$ & 402 & 255 & 1081 & 409 & 905 & 855 & 1500 & 2396 & 1090 \\
\hline $\mathbf{8 0 0}$ & 1397 & 1002 & 5202 & 1259 & 3717 & 3818 & 5300 & 6054 & 1627 \\
\hline
\end{tabular}

\section{Table: 9}

Above readings show that high vibrations are present at PBE. At all speeds vibrations in radial direction are higher than axial direction. High radial vibrations are present due to unbalance, misalignment and bending of the shaft. To determine the cause of high vibrations spectrum analysis was carried. Following are the spectrums taken at different speeds using FFT Analyzer with the support of Mcme2.0 software.

\subsection{Unbalanced spectrum at different speeds}

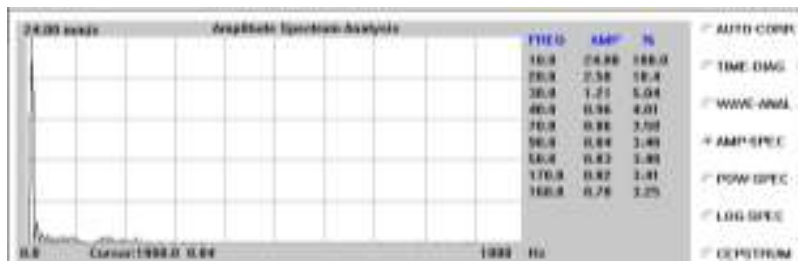

Spectrum in PBE HOZ direction at 600 rpm

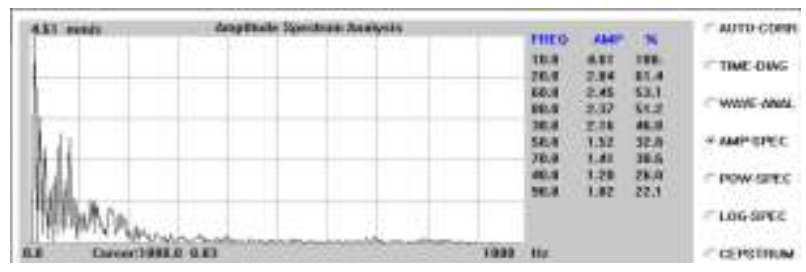

Spectrum in PBE AXL direction at 600 rpm

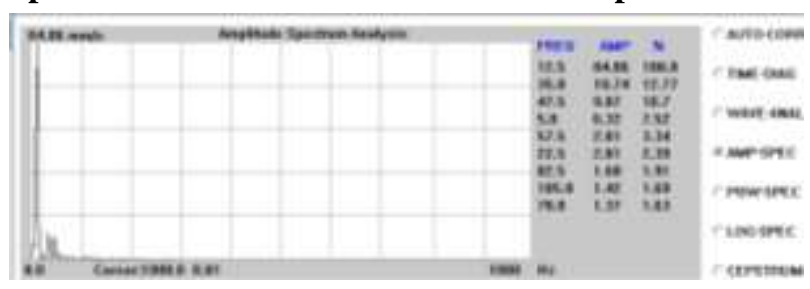

Spectrum in PBE VER direction at 700 rpm

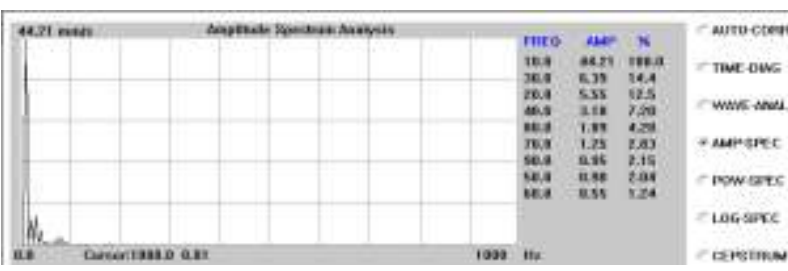

Spectrum in PBE VER direction at 600 rpm

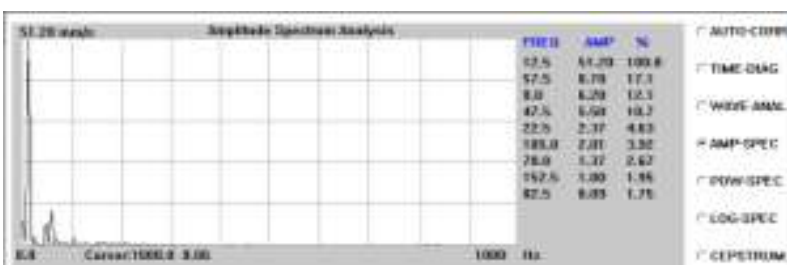

Spectrum in PBE HOZ direction at 700 rpm

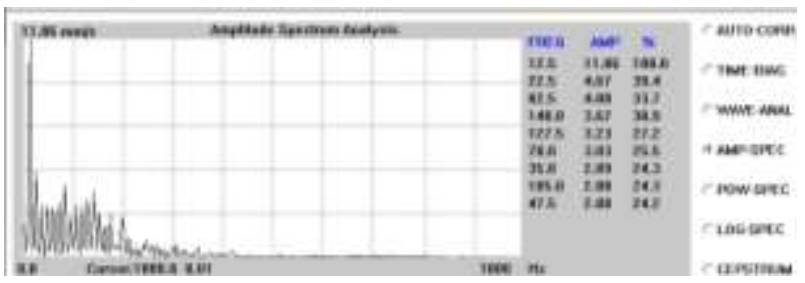

Spectrum in PBE AXL direction at 700 rpm 


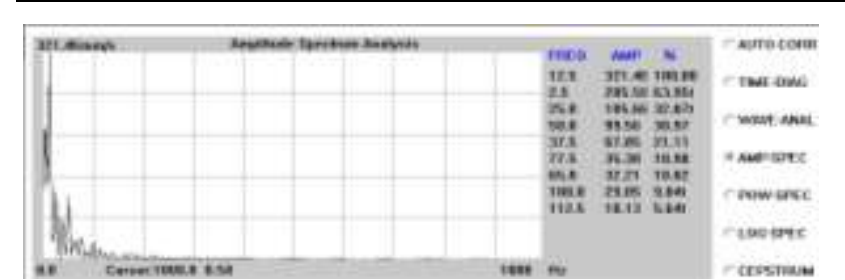

Spectrum in PBE HOZ direction at 800 rpm

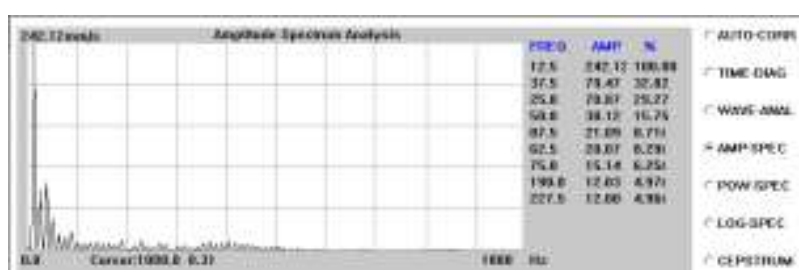

Spectrum in PBE VER direction at 800 rpm

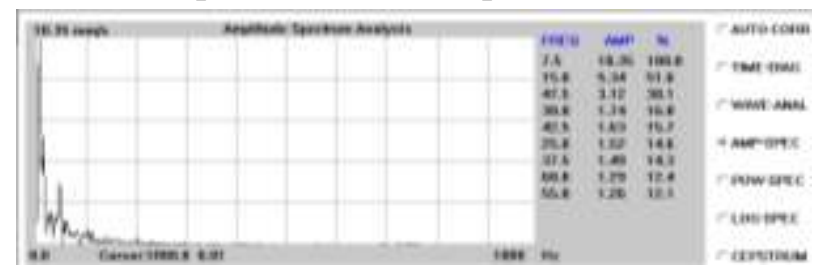

Spectrum in PBE AXL direction at 800 rpm

The following phase readings are also observed at PBE

\begin{tabular}{|c|ccccccc|c|}
\hline \multirow{2}{*}{$\begin{array}{c}\text { SPEED } \\
(\mathbf{r p m})\end{array}$} & \multicolumn{7}{|c|}{ DISPLACMENT in um } & \multirow{2}{*}{$\begin{array}{c}\text { PHASEANGLE } \\
\text { IN DEGREES }\end{array}$} \\
\cline { 2 - 8 } & $\mathbf{0}^{\mathbf{0}}$ & $\mathbf{3 0}^{\mathbf{0}}$ & $\mathbf{6 0}^{\mathbf{0}}$ & $\begin{array}{c}\mathbf{A t} \\
\mathbf{9 0}^{\mathbf{0}}\end{array}$ & $\mathbf{1 2 0}^{\mathbf{0}}$ & $\mathbf{1 5 0}^{\mathbf{0}}$ & $\mathbf{1 8 0}^{\mathbf{0}}$ & \\
\hline $\mathbf{6 0 0}$ & 307 & 324 & 395 & 549 & 476 & 384 & 310 & $90^{0}$ \\
\hline $\mathbf{7 0 0}$ & 796 & 876 & 603 & 683 & 1311 & 1001 & 703 & $60^{0}$ \\
\hline $\mathbf{8 0 0}$ & 907 & 1028 & 1245 & 1980 & 1720 & 1372 & 1260 & $90^{\circ}$ \\
\hline
\end{tabular}

Table: 10

\subsection{Observations from Spectrums}

1. In all the spectrums of pillow block end $1 \mathrm{X}$ and its harmonics are present.

2. No bearing defective frequency peaks are present in the pillow block spectrums.

3. The values at MNDE axial are high because of the looseness of the cup of motor.

4. In the pillow block at $800 \mathrm{rpm}$ vertical spectrum " $1 \mathrm{X}$ " is predominant and having highest value $6054 \mu \mathrm{m}$.

5. High " $1 \mathrm{X}$ " amplitudes in PBE horizontal and vertical spectrum indicates abnormal condition such as unbalance, misalignment, looseness or resonance condition.

6. To determine the exact cause of high vibrations phase readings are taken as shown in table above.

\subsection{Observation from Phase Analysis}

1. From the phase reading at the PBE it is observed that there is $90^{\circ}$ phase difference between the PBE horizontal and vertical.

2. $90^{\circ}$ phase difference between horizontal and vertical reveals that there is presence of an unbalance at PBE.

3. From the spectrum analysis and phase analysis it is conformed that there is a presence of mass unbalance in the PBE.

Rotor was removed and balanced weight is added diametrically opposite to unbalanced mass and vibration readings were taken after Balancing. Vibration Readings Are Shown In Following Table.

\subsection{Vibration Readings at Balanced Condition for Case 4}

\begin{tabular}{|l|c|c|c|c|c|c|c|c|c|}
\hline \multirow{2}{*}{ Speed } & \multicolumn{3}{|c|}{ MNDE } & \multicolumn{3}{c|}{ MDE } & \multicolumn{3}{c|}{ PBE } \\
\cline { 2 - 10 } & $\mathbf{H}$ & $\mathbf{V}$ & $\mathbf{A}$ & $\mathbf{H}$ & $\mathbf{V}$ & $\mathbf{A}$ & $\mathbf{H}$ & $\mathbf{V}$ & A \\
\hline $\mathbf{6 0 0}$ & 163 & 70.8 & 174 & 172 & 173 & 137 & 725 & 580 & 153 \\
\hline $\mathbf{8 0 0}$ & 192 & 143 & 473 & 184 & 406 & 368 & 830 & 1090 & 383 \\
\hline
\end{tabular}

\subsection{Balanced Spectrum at Different Speeds}

\section{Table: 11}

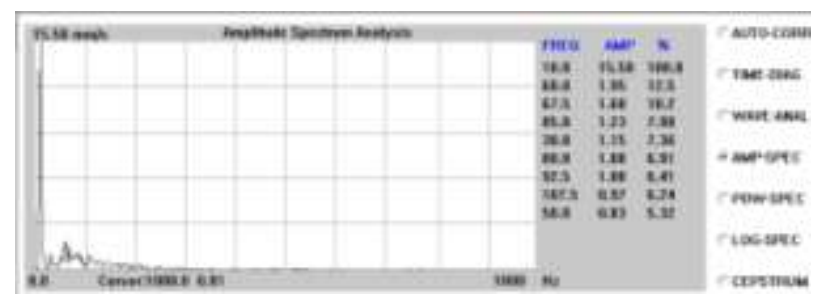

Spectrum in PBE HOZ direction at $600 \mathrm{rpm}$

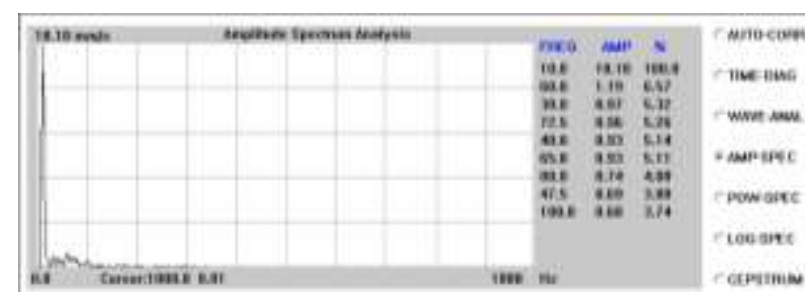

Spectrum in PBE VER direction at $600 \mathrm{rpm}$ 


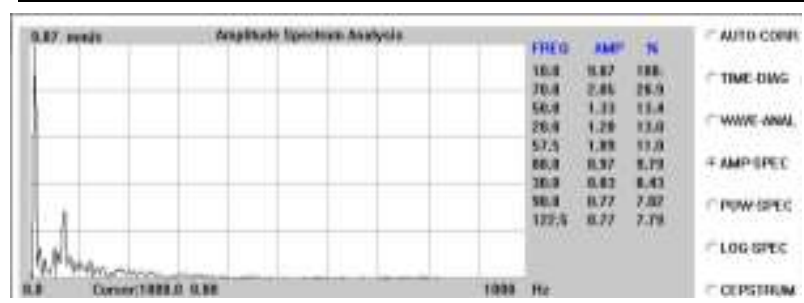

Spectrum in PBE AXL direction at 600 rpm

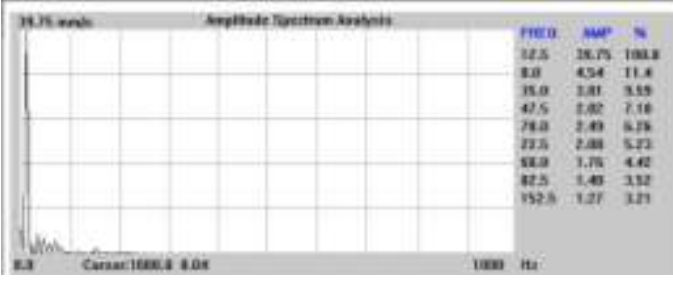

Spectrum in PBE VER direction at 700 rpm

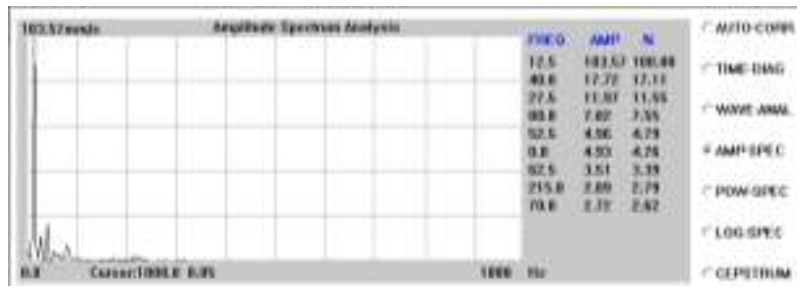

Spectrum in PBE HOZ direction at 800 rpm

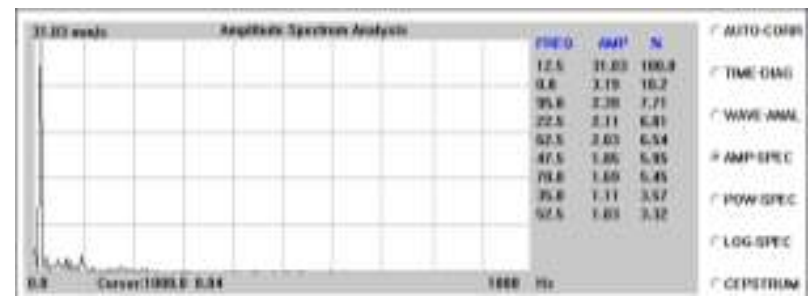

Spectrum in PBE HOZ direction at 700 rpm

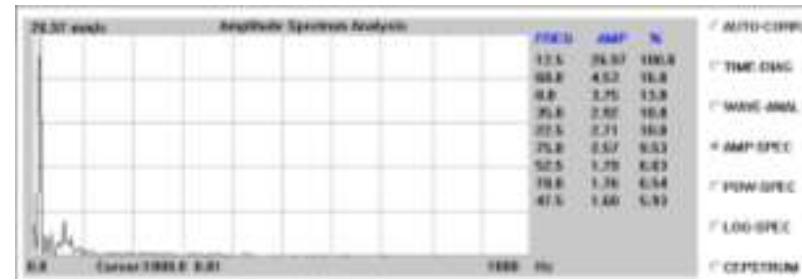

Spectrum in PBE AXL direction at 700 rpm

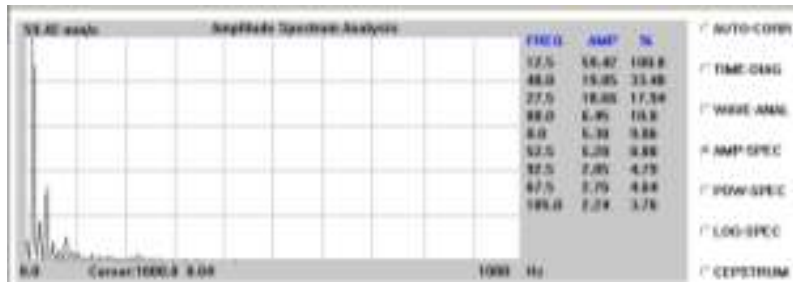

Spectrum in PBE VER direction at 800 rpm

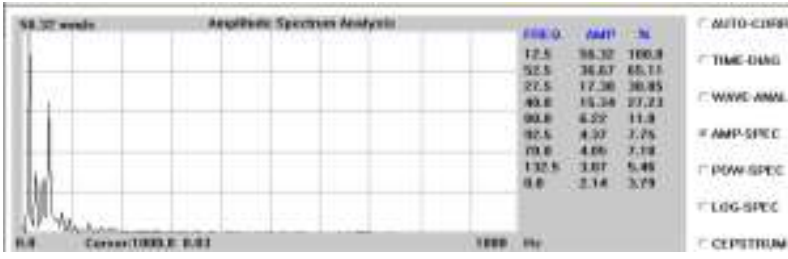

Spectrum in PBE AXL direction at 800 rpm

\subsection{Observations from Spectrums}

1. The values at MNDE axial are high because of the looseness of the cup of the motor at non-drive end.

2. All vibration readings show that the readings were reduced to normal level.

\subsection{Graphs show Vibration amplitude against speed, comparison with unbalance and balance}

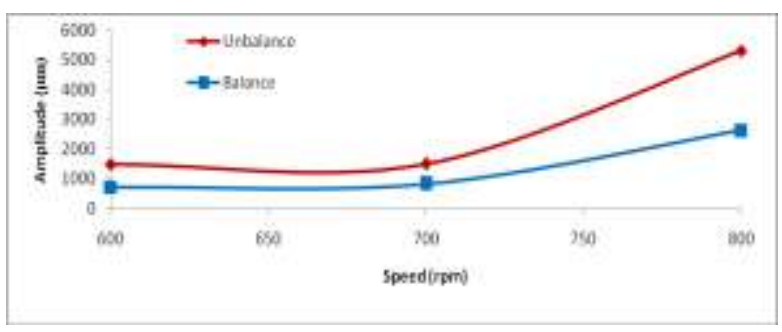

Vibration amplitude at PBE HOZ against speed

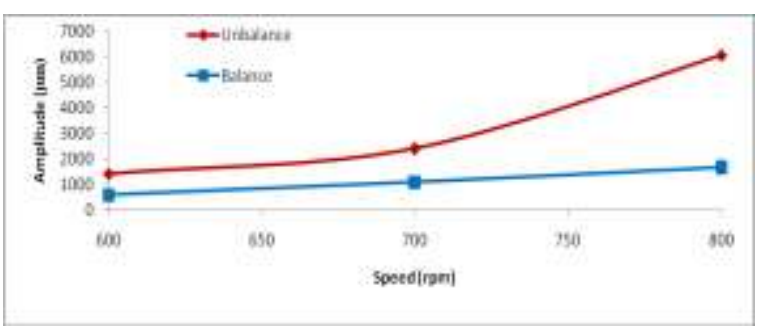

Vibration amplitude at PBE VER against speed

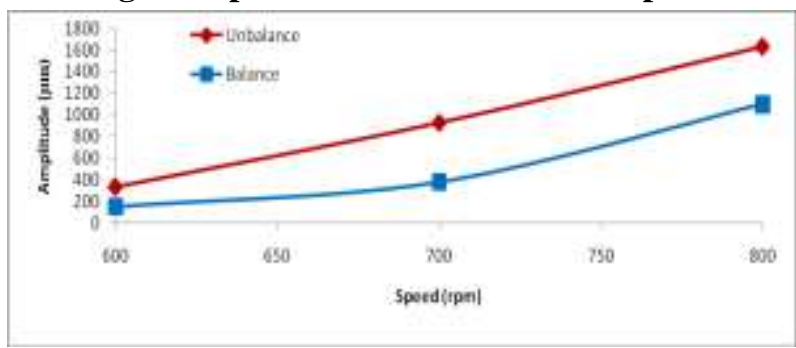

Vibration amplitude at PBE AXL against speed 


\section{Conclusion}

As the speed increases the amplitude at $1 \mathrm{X}$ is also increases for the same unbalance weight. This increase in amplitude value is because of the increase of centrifugal force. Since the system frequency is nearer to $900 \mathrm{rpm}$ due to the presence of resonance at this speed higher amplitudes were presented at 800rpm. Spectrum analysis shows that their presence of $1 \mathrm{X}$ amplitudes in radial directions. A high radial vibration with phase angle 900 causes the presence of unbalance. Rotor is balanced and vibration readings are taken after balancing. It was shown that amplitude of vibration is reduced drastically. The presence of unbalance causes deflected shape shaft. By measuring the maximum deflection from the shaft magnitude of unbalance can be determined using general solid mechanics formulae.

This paper outlines and showed the deflected shapes of shaft in different cases of presence of unbalance and the same is compared with deflected shapes of shaft in balanced conditions. This is very new method in determining the mechanical fault in rotating machines. This method reduces the maintenance cost drastically as it doesn't require sophisticated tools like FFT.

This is an NDT method to detect the fault in rotating machine. Hence Deflected shape of shaft method reduces the maintenance cost when it is applied to industries and improves the profit.

In this paper gyroscopic effect is not considered. If we consider the gyroscopic effect, the experimental values will be close to the theoretical values. The work may be extended for misalignment, looseness etc.

\section{References}

[1] Surendra N. Ganeriwala (Suri), Brian Schwarz \& Mark H. Richardson "Using Operating Deflection Shapes to Detect Unbalance in Rotating Equipment" Sound and Vibration, May 2009.

[2] Zhunag li, Surendra N. Ganeriwala \& Mark H. Richardson "Using Operating Deflection Shapes to Detect Unbalance in Rotating Equipment" Proceedings of International Modal Analysis Conference(XXVI),February,2008.

[3] William W. Clark, Joo-Hyung Kim, Roy D. Marangoni, "Active Control of Dynamic Bearing Loads in Rotating Machinery Using the Deflection Coefficient Method for Load Estimation", International Journal of Acoustics and Vibration.

[4] Kevin Gatzwiller, Brüel \& Kjær, "Measuring Torsional Operational Deflection Shapes of Rotating Shafts”, Brüel \& Kjær, World Headquarters, DK-2850 Nwum . Denmark.

[5] M.H. Richardson, "Is It a Mode Shape or an Operating Deflection Shape?" Sound and Vibration magazine, March, 1997.

[6] Seshendra Kumar.K.V.S, SundaraSiva Rao.B.S.K, "Experimental investigation of unbalance response of geared shaft rotor system", International Journal Of Applied Engineering Research, Dindigul, Volume 1, No 3, 2010

[7] Troy D. Feese P.E, Phillip E. Grazier, "Balance this: Case histories from difficult balance jobs" presented at $33^{\text {rd }}$ Turbo machinery Symposium. Sept., 2004.

[8] Gupta, K.D. Gupta and K. Athre, 1993. "Unbalance response of a dual rotor system: theory and experiment", Transactions J. Vibration Acoustics, 115: 427-435.

[9] D. G. Dorrell, "Experimental behavior of unbalanced magnetic pull in 3-phase induction motors with eccentric rotors and the relationship with tooth saturation," IEEE Trans. Energy Conversion, vol. 14, pp. 304-309, Sept. 1999.

[10] Ray D. Kelm, “Advanced Field Balancing Techniques”, P.E. Kelm Engineering Danbury, TX, 24-06-2008.

[11] Lev Nelik, Charles Jackson, "Effect of mechanical unbalance on vibrations, forces and reliability of a single stage centrifugal pump", Proceedings of Twelfth International Pump Users Symposium.

[12] Seok-Myeong Jang, Member, IEEE, Sung-Ho Lee, Han-Wook Cho, and Sung-Kook Cho, "Analysis of Unbalanced Force for HighSpeed Slotless Permanent Magnet Machine with Halbach Array”, IEEE TRANSACTIONS ON MAGNETICS, VOL. 39, NO. 5, SEPTEMBER 2003.

[13] Rao, T.N.Shiau and J.R. Chang, 1998. "Theoretical analysis of lateral response due to torsion excitation of geared rotor", Mechanism and Machine. Theory, 33(6): 761-783.Coupled lateral-torsional vibration of rotor.

[14] R.K.Biswas "vibration based condition monitoring of rotating machines" national conference on condition monitoring [NCCM2006] December 2006 pg no 34-40.

[15] R.A Collacat "condition monitoring” published by M c Graw Hill, New Delhi 1998.

[16] A.V.Barkov, N.A.Barkova, and A.Yu. Azovtsev, "Condition Monitoring and Diagnostics of Rotating Machines Using Vibration analysis", VAST, Inc., St. Petersburg, Russia, 1997.

[17] "A comparison of shaft deflection measurements" Chapter Three, The Modern Guide to Shaft Fitting.

[18] S. Edwards, A.W. Lees, M.I. Friswell, "Fault Diagnosis Of Rotating Machinery", Shock and Vibration Digest, Vol. 30, No. 1, pp. 4-13, 1998. 